\title{
Fertilidade do Solo e Produtividade de Milho em Sistemas de Adubação Verde No Norte de Minas Gerais ${ }^{1}$
}

\author{
Soil Fertility and Maize Yields in Green Manure Systems in Northern Minas Gerais
}

\author{
VALADARES, R.V. ${ }^{2}$, DUARTE, R.F. ${ }^{3}$, MENEZES, J.B.C. ${ }^{4}$, FERNANDES, L.A. ${ }^{5}$, TUFFI SANTOS, L.D. ${ }^{5}$, \\ SAMPAIO, R.A. ${ }^{5}$, MOTA, T.C. ${ }^{6}$ e ALMEIDA, R.M. ${ }^{6}$
}

\begin{abstract}
RESUMO - Baixas produtividades e deficiências de nitrogênio coexistem na cultura do milho, sobretudo em sistemas voltados para a agricultura de subsistência. Diante disso, com esta pesquisa buscou-se avaliar os efeitos da utilização de diferentes adubos verdes em sucessão com o milho, sob manejo de cultivo minimo e convencional, quanto ao aporte de nutrientes ao solo, ao estado nutricional e às características produtivas do milho para a produção de espigas. O experimento foi conduzido em campo, no Norte de Minas Gerais, em esquema de parcelas subdivididas com fatores dispostos no delineamento de blocos ao acaso, com três repetições. Os tratamentos principais foram: crotalária-juncea (Crotalaria juncea), feijão-de-porco (Canavalia ensiformes), nabo forrageiro (Rafhanus sativus), coquetel (crotalária, feijão-de-porco e nabo forrageiro) e plantas daninhas. As subparcelas foram constituídas pelos manejos da adubação verde, no cultivo mínimo ou convencional. Observou-se menor produtividade do milho quando da utilização do tratamento com plantas daninhas. De modo geral, foi identificado maior crescimento das plantas de milho no cultivo mínimo e maior estande no cultivo convencional, sem, contudo, efeito desses manejos na produtividade de espigas. Houve incremento nos teores superficiais de $\mathrm{P}$ e $\mathrm{K}$ no solo quando no manejo de cultivo minimo, mas melhor balanço $\mathrm{K} / \mathrm{Mg}$ nas plantas de milho no cultivo convencional.
\end{abstract}

Palavras-chave: Zea mays, espigas despalhadas, plantas de cobertura, nutrição

\begin{abstract}
Low yield and nitrogen deficiency coexist in corn crop, especially under subsistenceoriented systems. Thus, this work aimed to assess the effect of different types of green manure in maize succession, under minimum and conventional tillage, on soil nutrient input, nutritional state, and maize productive features for ear production. The experiment was arranged in a randomized block design, in a split-plot scheme, with three replications, under field conditions in northern Minas Gerais, Brazil. The main plots were constituted by the following types of green manure: sunnhep (Crotalaria juncea), jack beans (Canavalia ensiformes), fodder turnip (Rafhanus sativus), and green manure mixture (sunnhep + jack beans + fodder turnip), besides a treatment with weeds under fallow conditions. The subplots were constituted by conventional and minimum tillage management. Yield was affected by the different types of green manure, with lower values being identified in weed succession. In general, greater plant growth was observed in minimum tillage and higher maize plant density in conventional tillage. However, ear yield was not affected by soil tillage. Higher contents of potassium and phosphorus in 0-10 cm layer depth were observed under minimum tillage, while better $K / \mathrm{Mg}$ balance was observed on maize plants under conventional management.
\end{abstract}

Keywords: Zea mays, hulled ears, cover plants, nutrition.

1 Recebido para publicação em 20.7.2011 e aprovado em 21.6.2012.

2 Engo-Agro-. Estudante de Mestrado em Solos e Nutrição de Plantas, Dep. de Solos, Universidade Federal de Viçosa - DPS/UFV, $<$ rafaelvvaladares@hotmail.com>; ${ }^{3}$ Engํ-Agr ${ }^{-}$., M.Sc. em Ciências Agrárias, Estudante de Doutorado em Ciência do Solo, Dep. de Ciência do Solo, Universidade Federal de Lavras - DCS/UFLA; ${ }^{4}$ Eng - -Agr ${ }^{0}$., Estudante de Mestrado em Ciências Agrárias, Instituto de Ciências Agrárias, Universidade Federal de Minas Gerais - ICA/UFMG; ${ }^{5}$ Eng$^{0}$-Agr ${ }^{\circ}$., D. Sc., Professor, ICA/UFMG; ${ }^{6}$ Estudante de Agronomia, ICA/UFMG.

Planta Daninha, Viçosa-MG, v. 30, n. 3, p. 505-516, 2012 


\section{INTRODUÇÃO}

O Estado de Minas Gerais é tradicional na produção e consumo de milho-verde e representa a maior parte da produção do País, com aproximadamente $21,12 \%$ do total de espigas produzidas (Tsunechiro et al., 2002). Apesar da escassez de informações estatísticas acerca das produtividades alcançadas nesses sistemas de exploração, os levantamentos têm mostrado produtividades de grãos variáveis conforme a região fisiográfica desse Estado. Destacam-se as regiões do Alto Paranaíba, Triângulo, Noroeste e Sul, com produtividades médias de $6,4,7,1$ e $5,4 \mathrm{t} \mathrm{ha}^{-1}$, respectivamente (IBGE, 2009). O mesmo levantamento aponta modestos valores de produtividade para a região Norte do Estado de Minas Gerais, que, apesar das demandas impulsionadas pela avicultura e bovinocultura de corte, apresenta médias próximas a 1,9 $\mathrm{t} \mathrm{ha}^{-1}$. Entre as causas desse baixo rendimento encontra-se a interação entre fatores controláveis e não controláveis, representados pelo uso limitado de insumos em sistemas voltados para a agricultura de subsistência e pelo alto risco climático (Rao \& Mathuva, 2000; Faluba et al., 2010).

Dos fatores controláveis envolvidos no cultivo do milho, a deficiência de nitrogênio $(\mathrm{N})$ aparece relacionada às baixas produtividades alcançadas, sobretudo porque esse nutriente é o mais exigido e exportado pela cultura do milho (Fernandes et al., 1999; Al-Bakeir, 2003). Segundo Ohland et al. (2005), as respostas à fertilização com esse nutriente variam conforme o nível tecnológico do produtor, e as doses de $\mathrm{N}$ frequentemente oscilam entre 30 e $90 \mathrm{~kg} \mathrm{ha}^{-1}$. Entretanto, deve-se destacar o predomínio de lavouras para produção de espiga em pequena escala, em áreas que dificilmente extrapolam cinco hectares (Tsunechiro et al., 2002), cultivadas por agricultores familiares cuja renda torna impraticável a utilização de fertilizantes (Rao \& Mathuva, 2000).

A depleção nos teores de $\mathrm{N}$ nesses solos é comum e também observada em sistema mais tecnificados, condição essa explicada pelo manejo intensivo do solo e pela exportação maior que a restituição do nutriente - fato que justifica, em parte, os baixos estoques de matéria orgânica nesses sistemas (Fernandes et al., 1999).
A utilização de culturas de cobertura e a adubação mineral podem incrementar os estoques de N orgânico (Sainju et al., 2005), bem como o sistema de cultivo empregado. Nesse sentido, são relatados aumentos nos teores superficiais de matéria orgânica do solo $(0-7,5 \mathrm{~cm})$, maior imobilização de $\mathrm{N}$ pela biomassa microbiana, maior eficiência na utilização do fertilizante nitrogenado e produtividade de matéria seca da parte aérea de milho em sistemas sem revolvimento do solo (Fernandes et al., 1999).

Práticas como a adubação verde também têm se mostrado promissoras no aporte de $\mathrm{N}$ ao solo, significando aumento na absorção desse nutriente e incremento no rendimento de grãos na cultura do milho (Ohland et al., 2005). Cita-se, por exemplo, maior retorno financeiro em sistemas baseados na utilização de leguminosas para produção de milho-grão, em torno de 32 a 49\% mais rentáveis que o cultivo contínuo do milho solteiro sem o manejo com fontes sintéticas de N (Rao \& Mathuva, 2000). Adiciona-se a isso a necessidade de formular estratégias de cultivos de cereais em regiões com IDH baixo, pela maior importância nutricional assumida na dieta dessas populações (Garcia et al., 2006) - como exemplo, o Norte de Minas Gerais -, e a adubação verde como prática capaz de auxiliar no aumento da oferta de espigas.

Apesar dos beneficios diretos e indiretos advindos da adoção da adubação verde, essa tecnologia ainda tem sido subutilizada, possivelmente pelos custos e dificuldades na compra de sementes e pela ocupação da área sem retorno financeiro direto quando adotado o sistema de sucessão com adubos verdes sem propósito alimentar (Rao \& Mathuva, 2000). Assim, esta pesquisa vem destacar a possibilidade do aproveitamento de plantas daninhas na adubação verde do milho. A literatura ainda é escassa em trabalhos em que se utilizam plantas daninhas como fonte de nutrientes para o milho, bem como não esclarece os principais efeitos da adubação verde e dos manejos do solo sobre as características produtivas do milho colhido verde nas condições edafoclimáticas do Norte de Minas Gerais.

Diante disso, esta pesquisa teve por objetivo avaliar os efeitos da utilização de 
adubos verdes manejados em cultivo mínimo e convencional em rotação com o milho, quanto ao aporte de nutrientes ao solo, ao estado nutricional e às características produtivas do milho para a produção de espigas verdes.

\section{MATERIAL E MÉTODOS}

O experimento foi conduzido em campo, no período de agosto a maio, em Montes Claros, Minas Gerais (1640’50,92" de latitude sul, 43.50'22,36"W de longitude e altitude de 646.29 m). O clima local, segundo classificação de Köppen, é Aw, tropical de savana com inverno seco e verão chuvoso.

O ensaio foi instalado num Cambissolo Háplico, em área tradicionalmente cultivada em sistema orgânico, com adubação restrita à utilização de esterco bovino e fosfatos naturais, em sistema de rotação milho-quiabo. Os atributos determinados pela análise química e granulométrica da camada de $0-20 \mathrm{~cm}$ (antes da semeadura dos adubos verdes), segundo metodologia proposta pela Embrapa (1997), apresentaram os seguintes resultados: $\mathrm{pH}$ $\left(\mathrm{H}_{2} \mathrm{O}\right)=7,0 ; \mathrm{Ca}^{2+}=8,0 \mathrm{cmol}_{\mathrm{c}} \mathrm{dm}^{-3} ; \mathrm{Mg}=$ $1,5 \mathrm{cmol}_{\mathrm{c}} \mathrm{dm}^{-3} ; \mathrm{P}$ Mehlich $=25,4 \mathrm{mg} \mathrm{kg}^{-1}$; Prem $=24,0 \mathrm{mg} \mathrm{L}^{-1} ; \mathrm{K}=254 \mathrm{mg} \mathrm{kg}{ }^{-1}$; soma de bases $=10,15 \mathrm{cmol}_{\mathrm{c}} \mathrm{dm}^{-3}$; saturação por bases $=89 \%$; matéria orgânica $=3,39 \mathrm{dag} \mathrm{kg}^{-1}$; areia grossa $=5,9 \mathrm{dag}_{\mathrm{kg}}^{-1}$; areia fina $=50,1 \mathrm{dag} \mathrm{kg}^{-1}$; silte $=24,0$ dag $\mathrm{kg}^{-1} ;$ e argila $=20,0$ dag $\mathrm{kg}^{-1}$.

O delineamento experimental foi o de blocos ao acaso, em esquema de parcelas subdivididas, com três repetições. Cada bloco foi dividido em cinco parcelas casualizadas entre si, compreendidas por $20 \mathrm{~m}^{2}$ de área $(4 \times 5 \mathrm{~m})$, contendo os seguintes fatores: F1 crotalária (Crotalaria juncea), F2 - feijão-deporco (Canavalia ensiformes), F3 - nabo forrageiro (Rafhanus sativus), F4 - coquetel (crotalária, feijão-de-porco e nabo forrageiro) e F5 área de pousio - plantas daninhas (Tabela 1). As subparcelas foram constituídas pelos sistemas de manejo do solo: M1 - cultivo mínimo (utilização do "rolo-faca") e M2 - cultivo convencional (preparo do solo com duas gradagens com grade pesada).

Antecedendo a semeadura dos adubos verdes, foi feito o preparo do solo em área total, com uma aração e duas gradagens, sem adição de fertilizantes. A semeadura foi realizada de forma manual no espaçamento de 0,5 m entre linhas, e a densidade média de plântulas observada após 15 dias da emergência foi de 47, 8, 20 e 52 plântulas por metro linear, para crotalária, feijão-de-porco, nabo forrageiro e coquetel, respectivamente.

Tabela 1 - Valores médios de número de plantas e massa seca (g) de plantas daninhas encontradas no tratamento em pousio, em área de $1 \mathrm{~m}^{2}$. Montes Claros-MG, 2011

\begin{tabular}{|l|l|l|r|r|}
\hline \multicolumn{1}{|c|}{ Espécie } & \multicolumn{1}{|c|}{ Nome comum } & \multicolumn{1}{c|}{ NP } & MS lia \\
\hline Alternanthera tenella & Apaga-fogo & Amaranthaceae & 310 & 128,00 \\
\hline Brachiaria decumbens & Braquiária & Poaceae & 88 & 28,00 \\
\hline Euphorbia heterophylla & Leiteira & Euphorbiaceae & 8 & 3,64 \\
\hline Bidens subalternans & Picão-preto & Asteraceae & 52 & 24,00 \\
\hline Chloris gayana & Capim-pé-de-galinha & Poaceae & 68 & 72,00 \\
\hline Digitaria sanguinalis & Capim-colchão & Poaceae & 28 & 28,00 \\
\hline Sorghum arundinaceum & Falso-massambará & Poaceae & 2 & 7,22 \\
\hline Leonotis nepetifolia & Cordão-de-frade & Lamiaceae & 4 & 0,80 \\
\hline Emilia coccinea & Bela-emília & Asteraceae & 10 & 2,04 \\
\hline Emilia fosbergii & Seralha & Asteraceae & 26 & 3,65 \\
\hline Amaranthus spp. & Caruru & Amaranthaceae & 30 & 15,02 \\
\hline Ipomoea triloba & Corda-de-viola & Convolvulaceae & 6 & 4,65 \\
\hline Chamaesyce hyssopifolia & Erva-de-santa-luzia & Euphorbiaceae & 6 & 1,20 \\
\hline Sida spp. & Guanxuma & Malvaceae & 80 & 16,02 \\
\hline Merremia cissoides & Campainha & Convolvulaceae & 2 & 1,60 \\
\hline Total & & & & 3 \\
\hline
\end{tabular}


Na definição da data de corte dos adubos tomou-se como referência o florescimento da crotalária. Assim, aos 74 dias após a semeadura, quando do predomínio das plantas em floração (>50\%), procedeu-se ao corte, havendo ou não a incorporação, conforme o manejo pertinente a cada subparcela. Na mesma época foram coletadas amostras ao acaso, em área correspondente a $1 \mathrm{~m}^{2}$, para determinação da produtividade de massa fresca e seca da parte aérea dos adubos verdes e plantas daninhas. Posteriormente, foi retirada uma porção representativa do material de cada amostra, para estimativa do rendimento de massa seca. Essa subamostra foi pesada e colocada em estufa de ventilação forçada, a $65^{\circ} \mathrm{C}$, até atingir peso constante.

Antecedendo a semeadura do milho, aplicou-se um volume equivalente a 48,03 $\mathrm{m}^{3} \mathrm{ha}^{-1}$ de esterco bovino curtido nos sulcos de semeadura. As determinações analíticas do esterco, em termos de matéria seca, de acordo com metodologia proposta por Fermino et al. (2000), apresentaram os seguintes valores: $\mathrm{C} / \mathrm{N}=$ 14,$3 ; \mathrm{N}$ total $=2,5 \% ; \mathrm{P}_{2} \mathrm{O}_{5}=1,05 \% ; \mathrm{K}_{2} \mathrm{O}=1,33 \%$; $\mathrm{CaO}=1,41 \% ; \mathrm{MgO}=0,89 \% ; \mathrm{S}=0,1 \mathrm{~g} \mathrm{~kg}^{-1} ; \mathrm{B}=$ $53 \mathrm{mg} \mathrm{kg}^{-1} ; \mathrm{Zn}=96 \mathrm{mg} \mathrm{kg}^{-1} ; \mathrm{Fe}=1,29 \% ; \mathrm{Mn}=$ $243 \mathrm{mg} \mathrm{kg}^{-1} ; \mathrm{e} \mathrm{Cu}=40 \mathrm{mg} \mathrm{kg}^{-1}$.

A área de cada subparcela foi compreendida por $10,8 \mathrm{~m}^{2}(2,7 \times 4 \mathrm{~m})$, com três linhas de milho cultivar BR 106 no espaçamento de $0,9 \mathrm{~m}$ entre linhas e seis sementes por metro linear. Adotou-se como parcela útil a linha central, desconsiderando-se $0,5 \mathrm{~m}$ de cada extremidade. A semeadura do milho foi realizada 20 dias após o corte dos adubos verdes. Durante o cultivo, realizaram-se duas capinas com enxada para controle das plantas daninhas nas entrelinhas do milho, aos 15 e 45 dias após a semeadura.

A irrigação complementar foi feita por microaspersão tanto na fase de desenvolvimento dos adubos verdes quanto no cultivo do milho. Realizou-se a colheita das espigas verdes comerciais quando os grãos atingiram o estado "leitoso", entre 67 e 72 dias após a emergência das plântulas. Determinou-se o estande da cultura no momento da colheita (STAND), o número de espigas por hectare (NEHA), a produtividade de espigas empalhadas (PRODE, $t \mathrm{ha}^{-1}$ ) e a produtividade de espigas despalhadas
(PRODS, $\mathrm{t} \mathrm{ha}^{-1}$ ). Foram amostradas ao acaso seis espigas de cada subparcela, para determinação do comprimento médio de espigas despalhadas (COMP, $\mathrm{cm}$ ), diâmetro médio de espigas despalhadas (DIAM, $\mathrm{cm}$ ), comprimento médio do grão $(\mathrm{CMG}, \mathrm{cm})$, além do peso médio de espigas com palha (PMES, kg) e despalhadas (PMESC, kg).

Para avaliar o desenvolvimento da cultura, foram feitas medições do diâmetro do colmo e da altura das plantas aos 30 e 60 dias após a emergência. Com o objetivo de avaliar o estado nutricional da cultura, foram coletadas três amostras de folha por subparcela, quando da emissão dos estilos-estigmas, as quais foram compostas pelo terço médio da folha imediatamente abaixo da espiga superior, destituídas da nervura central, conforme metodologia sugerida por Malavolta et al. (1997). O diagnóstico do estado nutricional foi feito com a utilização das faixas de suficiência propostas por Martinez et al. (1999).

Imediatamente após a colheita do milhoverde foram feitas amostragens do solo na camada de $0-10 \mathrm{~cm}$ de profundidade, sendo representadas por uma amostra composta de cinco pontos aleatórios dentro da área de cada subparcela. A avaliação da fertilidade do solo foi baseada nas classes de interpretação da disponibilidade (Alvarez V. et al., 1999).

Os dados foram submetidos à análise de variância e, quando houve significância pelo teste $\mathrm{F}$, as médias dos tratamentos foram comparadas pelo teste de Tukey a $5 \%$ de probabilidade.

\section{RESULTADOS E DISCUSSÃO}

Os adubos verdes apresentaram diferentes valores de biomassa, naturalmente como uma função das características genéticas e do ambiente. Verificou-se relação entre os resultados e o período de florescimento; espécies mais precoces tenderam a apresentar maiores percentuais de massa seca (Tabela 2), provavelmente, em razão de se ter tomado como referência o florescimento da crotalária para determinação do período de corte das plantas. Em geral, a crotalária e as plantas daninhas apresentaram valores de rendimentos de massa fresca e seca superiores aos dos demais 
Tabela 2 - Produtividade de massa seca e verde $\left(\mathrm{t} \mathrm{ha}^{-1}\right)$ de adubos verdes. Montes Claros-MG, 2011

\begin{tabular}{|l|c|c|c|c|c|}
\hline \multicolumn{1}{|c|}{ Adubo verde } & Crotalária & Feijão-de-porco & Nabo forrageiro & Coquetel & Planta daninha \\
\hline Massa Verde** & $31,92 \mathrm{~b}$ & $26,47 \mathrm{bc}$ & $10,47 \mathrm{c}$ & $24,62 \mathrm{bc}$ & $50,07 \mathrm{a}$ \\
\hline Massa Seca** & $4,51 \mathrm{~A}$ & $2,04 \mathrm{BC}$ & $0,90 \mathrm{C}$ & $5,10 \mathrm{~A}$ & $3,36 \mathrm{AB}$ \\
\hline
\end{tabular}

Letras minúsculas comparam as médias de produtividade de matéria verde e maiúsculas comparam as médias de produtividade de matéria seca. Médias seguidas de mesma letra na linha não diferem estatisticamente entre si pelo teste de Tukey a $5 \%$. $* *$ significativo a $1 \%$ de probabilidade pelo teste $\mathrm{F}$.

adubos. Todavia, o coquetel de adubos apresentou o maior rendimento de massa seca, considerado estatisticamente igual à crotalária e às plantas daninhas, com proporção média de $20,71 \%$ de massa seca no total do material fresco.

Embora o feijão-de-porco tenha proporcionado rápida cobertura do solo, observou-se baixo rendimento de massa seca, possivelmente pela menor proporção de plantas em estádio de maturidade fisiológica. Por sua vez, o nabo forrageiro floresceu precocemente e mostrou o segundo maior percentual de massa seca, o que, contudo, resultou em baixa produção por área. Esses resultados estão, em parte, relacionados à época desaconselhada para o cultivo do nabo forrageiro (Sullivan, 2003), embora, no inverno, em condições de cerrado, a seca possa inviabilizar a produção de biomassa por parte dessa espécie. Nesse particular, a literatura traz diferentes valores de produtividade para todas as espécies em estudo - condição normal, uma vez que os ensaios são conduzidos em condições climáticas variadas (Alvarenga et al., 1995).

Em sistemas voltados para a utilização de plantas de cobertura como forma de adubação, a exemplo das sucessões utilizadas neste ensaio, é interessante observar as variações no comportamento das plantas utilizadas para esse fim, notadamente no que concerne às eficiências no aproveitamento dos recursos de crescimento e na composição da biomassa, como na proporção de carbono e nitrogênio, bem como no tipo de cadeias carbônicas predominantemente encontradas no material vegetal (Sullivan, 2003). Essas diferenças entre adubos, naturalmente, podem levar a diferentes taxas de mineralização e/ou a alterações nas condições fisicas do solo, e, consequentemente, a liberação dos nutrientes pode estar em maior ou em menor sincronia com os requerimentos da cultura de interesse econômico.

Nesse sentido, observou-se que o milho cultivado nas parcelas onde houve maior deposição de palhada apresentou maior crescimento em altura e diâmetro do coleto (Tabela 3). A maior deposição de restos vegetais na superficie do solo provavelmente permitiu maior retenção de umidade, visto que, nos tratamentos sob cultivo mínimo e com maior produção de palhada, verificou-se visualmente maior permanência do material e tendente maior manutenção da umidade do solo. Essa informação é bastante importante para a cultura do milho, uma vez que a umidade do solo é um dos principais fatores a influenciar o desenvolvimento da inflorescência masculina, que se inicia próximo aos 14 dias após a emergência (DAE) - período em que também é definido o número de folhas (Ferraz, 1966). Bergamaschi et al. (2004), por exemplo, consideram a água o principal fator a condicionar as safras de milho cultivado no verão.

Segundo Alvarenga et al. (1995), a velocidade de cobertura e o percentual de cobertura do solo podem constituir base para escolha de adubos verdes. Além da proteção contra processos erosivos, esses autores destacam o papel das raízes, notadamente desenvolvidas, na estabilização de agregados do solo pela ação mecânica e/ou pela excreção de substâncias com ação cimentante, que podem influenciar o comportamento da água no solo.

Aparentemente, a prática da adubação verde proporcionou melhores condições fisicas, beneficiando o desenvolvimento do milho no manejo de cultivo mínimo em sucessão aos tratamentos crotalária, feijão-de-porco, plantas daninhas e coquetel (Tabela 3). Nesse ponto, vale lembrar que, quando o meristema apical 
Tabela 3 - Altura $(\mathrm{cm})$ e diâmetro do coleto $(\mathrm{cm})$ do milho aos 30 e 60 dias, em função da adubação verde e do sistema de manejo. Montes Claros-MG, 2011

\begin{tabular}{|c|c|c|c|c|c|c|}
\hline & \multirow{2}{*}{\multicolumn{2}{|c|}{ Variáveis }} & \multicolumn{2}{|c|}{ Altura } & \multicolumn{2}{|c|}{ Diâmetro } \\
\hline & & & 30 dias ** & 60 dias $* *$ & 30 dias $* *$ & $60 \operatorname{dias}^{\mathrm{ns}}$ \\
\hline \multirow{10}{*}{$\begin{array}{l}\text { Adubos Verdes e } \\
\text { Manejos (M1 = } \\
\text { cultivo mínimo e } \\
\text { M2 = cultivo } \\
\text { convencional) }\end{array}$} & \multirow{2}{*}{ Crotalária } & M1 & $42,78 \mathrm{AB}$ & $239,56 \mathrm{~A}$ & $2,39 \mathrm{~A}$ & 2,54 \\
\hline & & M2 & $38,22 \mathrm{AB}$ & $220,78 \mathrm{~A}$ & $2,18 \mathrm{~A}$ & 2,30 \\
\hline & \multirow{2}{*}{ Feijão-de-porco } & M1 & $44,67 \mathrm{~A}$ & $246,89 \mathrm{~A}$ & $2,39 \mathrm{~A}$ & 2,53 \\
\hline & & M2 & $40,67 \mathrm{~A}$ & $208,00 \mathrm{~A}$ & $2,11 \mathrm{~A}$ & 2,30 \\
\hline & \multirow{2}{*}{ Nabo forrageiro } & M1 & $35,56 \mathrm{~B}$ & $202,33 \mathrm{~B}$ & $1,84 \mathrm{~B}$ & 2,36 \\
\hline & & M2 & $35,22 \mathrm{~B}$ & $183,00 \mathrm{~B}$ & $1,89 \mathrm{~B}$ & 2,33 \\
\hline & \multirow{2}{*}{ Coquetel } & M1 & $45,67 \mathrm{~A}$ & $233,56 \mathrm{~A}$ & $2,41 \mathrm{~A}$ & 2,67 \\
\hline & & M2 & $39,00 \mathrm{~A}$ & $203,33 \mathrm{~A}$ & $2,01 \mathrm{~A}$ & 2,25 \\
\hline & \multirow{2}{*}{ Plantas daninhas } & M1 & $36,00 \mathrm{AB}$ & $210,00 \mathrm{AB}$ & $1,73 \mathrm{~B}$ & 2,47 \\
\hline & & M2 & $36,00 \mathrm{AB}$ & $204,33 \mathrm{AB}$ & $1,73 \mathrm{~B}$ & 2,50 \\
\hline \multirow{2}{*}{\multicolumn{2}{|c|}{ Média* }} & M1 & 40,93 & $226,47 \mathrm{a}$ & $2,15 \mathrm{a}$ & 2,51 \\
\hline & & M2 & 37,82 & $203,89 \mathrm{~b}$ & $1,98 \mathrm{~b}$ & 2,34 \\
\hline \multicolumn{3}{|c|}{$\mathrm{CV}(\mathrm{a}) \%$} & 14,99 & 7,64 & 7,99 & 7,04 \\
\hline
\end{tabular}

Letras minúsculas comparam as médias dos sistemas de manejo do material vegetal (M1 e M2) pelo teste F. Médias maiúsculas seguidas de mesma letra na coluna não diferem estatisticamente entre si pelo teste de Tukey a $5 \%$. ${ }^{* *}$ significativo a $1 \%$. ${ }^{*}$ significativo a $5 \%$. ${ }^{\text {ns }}$ não significativo pelo teste $\mathrm{F}$ a $5 \%$ de probabilidade.

está sob a superfície do solo, a condição térmica é o principal fator a influenciar a taxa de desenvolvimento do milho (Forsthofer et al., 2004). Além dos efeitos na retenção de água, a utilização de adubos em cobertura pode atuar na estabilização da temperatura do solo (Sullivan, 2003).

Conforme observado na Tabela 3, a cultura apresentou pequeno crescimento até 30 dias após a emergência (DAE); após esse período, houve rápido crescimento. De acordo com Malavolta \& Gargantini (1966) e Al-Bakeir (2003), há reduzida absorção de nutrientes nessa fase, o que leva a reforçar a hipótese de que houve significativa variação na umidade e/ou temperatura do solo, a ponto de produzir diferenças no desenvolvimento das plantas de milho. Conforme observações feitas por Baker \& Musgrave (1964), o milho tem redução média de $50 \%$ da capacidade fotossintética quando do aumento da tensão da água no solo de 0,3 para 1 atm. Somado a isso está a arquitetura radicular típica de fasciculação, que, sobretudo nos estádios iniciais de desenvolvimento, concentra-se na porção superficial do solo (Ferraz, 1966). Os resultados desta pesquisa mostram que as diferenças produzidas no início do desenvolvimento da cultura do milho, aos $30 \mathrm{DAE}$, são mantidas quando da emissão do pendão, próximo aos 60 DAE. Nesse último período não foram observadas diferenças significativas para o diâmetro, o que provavelmente está relacionado à translocação das reservas do colmo para as partes reprodutivas da planta. Dessa forma, é ideal que em trabalhos dessa natureza as condições de umidade e temperatura do solo sejam avaliadas com maior rigor.

Quanto às características agronômicas do milho, as sucessões às leguminosas, ao nabo forrageiro e ao coquetel resultaram, de modo geral, em maiores médias (Tabela 4). A utilização dos diferentes adubos e sistemas de manejo produziu considerável variação no estande. Nesse aspecto, não se verificou diferença entre as leguminosas e o nabo forrageiro. A variável estande foi bastante influenciada pelos tratamentos e associa-se fortemente às diferenças de produtividade aqui descritas. Comparando os valores máximos observados, na sucessão ao feijão-de-porco, com o tratamento com plantas daninhas, verificou-se redução de aproximadamente $21,15 \%$ do estande. De forma geral, os menores valores de estande, número de espigas por hectare e produtividade de espigas despalhadas foram observados em sucessão às plantas daninhas (Tabela 4). 
Esses resultados podem, em parte, estar associados à interferência da flora infestante sobre o milho. Plantas com propagação vegetativa, como a braquiarinha e o falsomassambará, dificilmente serão controladas por manejos mecânicos, como a utilização do rolo-faca, tendo por consequência maior frequência e dominância nesses tratamentos. Ferreira e Aquila (2000) explicam que as plantas preexistentes e seus compostos químicos liberados podem determinar o modelo de sucessão numa determinada área. Evidências experimentais sugerem a atividade nociva de algumas plantas daninhas, como é o caso das espécies Amaranthus retroflexus e Brachiaria decumbens em plantas de milho e eucalipto, respectivamente (BHOWMIK; DOLL, 1982, 1984; SOUZA et al., 2003). Assim, a produção de aleloquímicos pelas plantas daninhas pode explicar em parte o menor estande de milho em parcelas cultivadas em sucessão a essa vegetação.

O comprimento e o diâmetro médio de espigas despalhadas não apresentaram variação em função dos tratamentos (Tabela 5). Já o comprimento médio de grãos de milho apresentou maiores valores quando em sucessão ao feijão-de-porco e às plantas daninhas, independentemente do manejo dos resíduos.
Na avaliação dos atributos químicos do solo após o cultivo do milho, verificaram-se diferenças entre os tratamentos (Tabela 6). Os maiores valores de nutrientes e de matéria orgânica foram encontrados nos sistemas de cultivo mínimo, com destaque para o fósforo disponível e o potássio trocável. Embora tenham sido verificadas diferenças estatísticas, as classes de interpretação agronômica para os teores de matéria orgânica, Ca e Mg não variaram com o manejo e a adubação verde, sendo classificados como "bom" para os de matéria orgânica e "muito bom" para os de cálcio e magnésio, de acordo com Alvarez V. et al. (1999).

As classes de interpretação da disponibilidade para fósforo disponivel diferiram entre os sistemas de cultivo minimo e convencional: "bom" e "médio", respectivamente (Tabela 6). Nesse ponto em particular, considerandose a estimativa da capacidade de fixação de fosfatos pelo solo, fornecida pela análise de fósforo remanescente, é provável que a oxidação da biomassa dos adubos verdes na superficie do solo em cultivo mínimo tenha contribuído para maior disponibilidade desse nutriente. Além disso, a menor fixação do fósforo no sistema de cultivo mínimo pode ser atribuída à mineralização mais lenta da biomassa vegetal na superficie do solo, em

Tabela 4 - Estande da cultura do milho (STAND), número de espigas por hectare (NEHA), produtividade de espigas empalhadas (PRODE, $\mathrm{t} \mathrm{ha}^{-1}$ ) e produtividade de espigas despalhadas (PRODS, $\mathrm{t} \mathrm{ha}^{-1}$ ), em função dos adubos verdes e dos sistemas de manejo. Montes Claros-MG, 2011

\begin{tabular}{|c|c|c|c|c|c|c|}
\hline & \multicolumn{2}{|c|}{ Variáveis } & STAND* & $\mathrm{NEHA}^{* *}$ & PRODE* & PRODS* \\
\hline \multirow{10}{*}{$\begin{array}{l}\text { Adubos Verdes e } \\
\text { Manejos (M1 = } \\
\text { cultivo mínimo e } \\
\text { M2 = cultivo } \\
\text { convencional) }\end{array}$} & \multirow{2}{*}{ Crotalária } & M1 & $42.593 \mathrm{AB}$ & $50.000 \mathrm{~A}$ & $12,774 \mathrm{~A}$ & $9,065 \mathrm{~A}$ \\
\hline & & M2 & $43.519 \mathrm{AB}$ & $44.444 \mathrm{~A}$ & $12,346 \mathrm{~A}$ & $8,184 \mathrm{~A}$ \\
\hline & \multirow{2}{*}{ Feijão-de-porco } & M1 & $50.000 \mathrm{AB}$ & $52.778 \mathrm{~A}$ & $13,563 \mathrm{~A}$ & $10,465 \mathrm{~A}$ \\
\hline & & M2 & $46.296 \mathrm{AB}$ & $43.519 \mathrm{~A}$ & $9,689 \mathrm{~A}$ & $7,256 \mathrm{~A}$ \\
\hline & \multirow{2}{*}{ Nabo forrageiro } & M1 & $43.519 \mathrm{~A}$ & $43.519 \mathrm{~A}$ & $10,504 \mathrm{~A}$ & $7,773 \mathrm{AB}$ \\
\hline & & M2 & $55.556 \mathrm{~A}$ & $49.074 \mathrm{~A}$ & $10,761 \mathrm{~A}$ & $6,788 \mathrm{AB}$ \\
\hline & \multirow{2}{*}{ Coquetel } & M1 & $37.963 \mathrm{AB}$ & $43.519 \mathrm{AB}$ & $11,835 \mathrm{~A}$ & 7,902 AB \\
\hline & & M2 & $43.519 \mathrm{AB}$ & $41.667 \mathrm{AB}$ & $10,117 \mathrm{~A}$ & 7,109 AB \\
\hline & \multirow{2}{*}{ Plantas daninhas } & M1 & $31.481 \mathrm{~B}$ & $23.148 \mathrm{~B}$ & $4,433 \mathrm{~B}$ & $3,858 \mathrm{~B}$ \\
\hline & & M2 & $44.444 \mathrm{~B}$ & $38.889 \mathrm{~B}$ & 9,789 B & $6,896 \mathrm{~B}$ \\
\hline \multirow{2}{*}{\multicolumn{2}{|c|}{ Média }} & M1 & $41.111 \mathrm{a}$ & 42.593 & 10,622 & 7,813 \\
\hline & & M2 & $46.667 \mathrm{~b}$ & 43.519 & 10,540 & 7,247 \\
\hline \multicolumn{3}{|c|}{$\mathrm{CV}$ (a) $\%$} & 15,42 & 27,22 & 27,52 & 33,67 \\
\hline
\end{tabular}

Letras minúsculas comparam as médias dos sistemas de manejo do material vegetal (M1 e M2) pelo teste F. Médias maiúsculas seguidas de mesma letra na coluna não diferem estatisticamente entre si pelo teste de Tukey a 5\%. ** significativo a $1 \%$. * significativo a $5 \%$. ns não significativo pelo teste $\mathrm{F}$ a $5 \%$ de probabilidade. 
Tabela 5 - Comprimento médio de espigas despalhadas (COMP, $\mathrm{cm}$ ), diâmetro médio de espigas despalhadas (DIAM, cm), comprimento médio dos grãos (CMG, cm), peso médio de espigas com casca (PMES, $\mathrm{kg}$ ) e peso médio de espigas sem casca (PMESC, kg), em função dos adubos verdes e dos sistemas de manejo. Montes Claros-MG, 2011

\begin{tabular}{|c|c|c|c|c|c|c|c|}
\hline & \multicolumn{2}{|c|}{ Variáveis } & $\mathrm{COMP}^{\mathrm{ns}}$ & DIAM $^{\text {ns }}$ & CMG* $^{*}$ & PMES* & $\mathrm{PMESC}^{\mathrm{ns}}$ \\
\hline \multirow{10}{*}{$\begin{array}{l}\text { Adubos Verdes e } \\
\text { Manejos (M1 = } \\
\text { cultivo mínimo e } \\
\text { M2 = cultivo } \\
\text { convencional) }\end{array}$} & \multirow{2}{*}{ Crotalária } & M1 & 17,86 & 4,23 & $1,02 \mathrm{ABa}$ & $0,255 \mathrm{Aa}$ & 0,182 \\
\hline & & M2 & 17,98 & 4,15 & $0,89 \mathrm{Cb}$ & $0,284 \mathrm{Aa}$ & 0,182 \\
\hline & \multirow{2}{*}{ Feijão-de-porco } & M1 & 17,93 & 4,37 & $1,09 \mathrm{ABa}$ & $0,262 \mathrm{ABa}$ & 0,196 \\
\hline & & M2 & 17,64 & 4,16 & $1,05 \mathrm{ABCa}$ & $0,222 \mathrm{ABa}$ & 0,168 \\
\hline & \multirow{2}{*}{ Nabo forrageiro } & M1 & 18,15 & 4,21 & $0,94 \mathrm{Ba}$ & $0,236 \mathrm{Ba}$ & 0,174 \\
\hline & & M2 & 16,49 & 3,90 & $0,98 \mathrm{BCa}$ & $0,218 \mathrm{Ba}$ & 0,134 \\
\hline & \multirow{2}{*}{ Coquetel } & M1 & 17,02 & 4,26 & $1,06 \mathrm{ABa}$ & $0,271 \mathrm{ABa}$ & 0,181 \\
\hline & & M2 & 17,40 & 4,24 & $1,05 \mathrm{ABCa}$ & $0,242 \mathrm{ABa}$ & 0,169 \\
\hline & \multirow{2}{*}{ Plantas daninhas } & M1 & 17,70 & 4,13 & $1,05 \mathrm{ABb}$ & $0,192 \mathrm{Bb}$ & 0,167 \\
\hline & & M2 & 17,05 & 4,38 & $1,16 \mathrm{ABa}$ & $0,252 \mathrm{Ba}$ & 0,177 \\
\hline \multirow{2}{*}{\multicolumn{2}{|c|}{ Média }} & M1 & 17,73 & 4,24 & 1,03 & 0,243 & 0,180 \\
\hline & & $\mathrm{M} 2$ & 17,31 & 4,17 & 1,02 & 0,244 & 0,166 \\
\hline \multicolumn{3}{|c|}{$\mathrm{CV}$ (a) \% } & 4,63 & 4,69 & 5,39 & 10,72 & 10,64 \\
\hline
\end{tabular}

Letras minúsculas comparam as médias dos sistemas de manejo do material vegetal (M1 e M2) pelo teste F. Médias maiúsculas seguidas de mesma letra na coluna não diferem estatisticamente entre si pelo teste de Tukey a $5 \%$. $* *$ significativo a $1 \%$. $*$ significativo a $5 \%$. ns não significativo pelo teste $\mathrm{F}$ a $5 \%$ de probabilidade.

comparação àquela incorporada. De acordo com Andrade et al. (2002), os produtos da decomposição dos resíduos orgânicos, como os ácidos orgânicos, bloqueiam os sítios de fixação de fosfatos e, consequentemente, podem influir nos valores de $\mathrm{P}$ remanescente (estimativa da capacidade de adsorção de fosfatos pelos solos) e, por isso, no $\mathrm{P}$ disponível para as plantas.

No caso do potássio, semelhantemente ao fósforo disponivel, verificaram-se diferenças significativas apenas entre os sistemas de manejo, sendo os maiores valores obtidos no sistema de cultivo minimo (Tabela 6). Embora não tenham sido constatadas diferenças estatísticas entre os adubos, os teores de $\mathrm{K}$ no tratamento coquetel foram bastante inferiores aos do tratamento com plantas daninhas. Independentemente dos tratamentos, os teores de potássio trocável foram classificados quanto a disponibilidade como "muito boa", de acordo com Alvarez V. et al. (1999).

Essa maior concentração de fósforo e potássio no sistema de cultivo mínimo pode ser explicada pela forma de movimentação predominante desses íons: a difusão. Contudo, deve-se ter em mente que incrementos mesmo que muito baixos nos teores de matéria orgânica em sistemas sem revolvimento do solo, como observado na Tabela 6 , podem favorecer a maior adsorção de $\mathrm{K}$ e, para $\mathrm{o}$ fósforo, o menor contato com a fase mineral do solo, resultando em menores perdas por fixação, para o P, e lixiviação, para o K (Novais et al., 2007). Rosolem et al. (2006), por exemplo, citam a maior concentração de $\mathrm{K}$ no solo quando da utilização de cobertura morta de milheto.

Em condições tropicais, em solos de baixa CTC, as perdas de K são preocupantes, porque, além de não compor moléculas orgânicas (Epstein \& Bloom, 2006), o K não é preferencialmente retido nos coloides do solo. Por isso, em sistema de incorporação, onde há aumento da macroporosidade do solo, há também maior possibilidade de lixiviação desse íon ao longo do perfil. Deve-se ter em conta também que em solos tropicais a CTC reduz com o aumento da profundidade do perfil, de modo que a matéria orgânica tem fundamental importância por manter o K na região de maior absorção de nutrientes pelas raízes (Novais et al., 2007).

Apesar das diferenças na fertilidade, não foram constatados efeitos significativos dos adubos verdes e dos sistemas de manejo do 
Tabela 6 - Acidez ativa (pH), fósforo Mehlich (P Mehlich), fósforo remanescente (P rem), potássio (K), cálcio (Ca), magnésio (Mg), acidez potencial trocável (Al), acidez potencial total (H+Al) e matéria orgânica do solo (MOS), em função da adubação verde e dos sistemas de manejo. Montes Claros-MG, 2011

\begin{tabular}{|c|c|c|c|c|c|c|c|}
\hline & \multirow{2}{*}{\multicolumn{2}{|c|}{ Variáveis }} & \multirow{2}{*}{$\mathrm{pH}^{\mathrm{ns}}$} & P Melich** & $\mathrm{P}-\mathrm{rem}^{\mathrm{ns}}$ & $\mathrm{K}^{*}$ & \\
\hline & & & & $\left(\mathrm{mg} \mathrm{dm}^{-3}\right)$ & $\left(\mathrm{mg} \mathrm{L}^{-1}\right)$ & $\left(\mathrm{mg} \mathrm{dm}^{-3}\right)$ & $\left(\mathrm{cmol}_{\mathrm{c}} \mathrm{dm}^{-3}\right)$ \\
\hline \multirow{25}{*}{$\begin{array}{l}\text { Adubos Verdes e } \\
\text { Manejos (M1 = } \\
\text { cultivo mínimo e } \\
\text { M2 = cultivo } \\
\text { convencional) }\end{array}$} & \multirow{2}{*}{ Crotalária } & M1 & 7,37 & 16,60 & 24,33 & 259,67 & 6,67 \\
\hline & & M2 & 7,50 & 14,73 & 21,07 & 158,67 & 7,37 \\
\hline & \multirow{2}{*}{ Feijão-de-porco } & M1 & 7,60 & 16,43 & 22,63 & 279,67 & 7,57 \\
\hline & & M2 & 7,33 & 12,73 & 21,40 & 138,67 & 6,73 \\
\hline & \multirow{2}{*}{ Nabo forrageiro } & M1 & 7,40 & 22,77 & 22,27 & 197,67 & 6,73 \\
\hline & & M2 & 7,47 & 13,37 & 21,97 & 187,67 & 6,23 \\
\hline & \multirow{2}{*}{ Coquetel } & M1 & 7,57 & 16,63 & 23,80 & 183,00 & 6,63 \\
\hline & & M2 & 7,40 & 11,40 & 21,97 & 176,33 & 6,70 \\
\hline & \multirow{2}{*}{ Plantas daninhas } & M1 & 7,50 & 17,50 & 22,67 & 207,67 & 7,27 \\
\hline & & M2 & 7,57 & 8,10 & 23,03 & 205,33 & 6,33 \\
\hline & \multirow{2}{*}{ Média } & M1 & 7,49 & $17,99 \mathrm{a}$ & 23,14 & $225,53 \mathrm{a}$ & 6,97 \\
\hline & & M2 & 7,45 & $12,07 \mathrm{~b}$ & 21,89 & $173,33 \mathrm{~b}$ & 6,67 \\
\hline & \multicolumn{2}{|l|}{$\mathrm{CV}$ (a) $\%$} & 4,22 & 23,00 & 7,35 & 31,31 & 12,34 \\
\hline & \multirow{2}{*}{\multicolumn{2}{|c|}{ Variáveis }} & $\mathrm{Mg}^{\mathrm{ns}}$ & $\mathrm{Al}^{\mathrm{ns}}$ & $\mathrm{H}+\mathrm{Al}^{\mathrm{ns}}$ & \multicolumn{2}{|c|}{$\operatorname{MOS}^{\mathrm{ns}}$} \\
\hline & & & \multicolumn{3}{|c|}{$\left(\mathrm{cmol}_{\mathrm{c}} \mathrm{dm}^{-3}\right)$} & \multicolumn{2}{|c|}{$\left(\right.$ dag kg $\left.^{-1}\right)$} \\
\hline & \multirow{2}{*}{ Crotalária } & M1 & 2,13 & 0,00 & 1,04 & \multicolumn{2}{|c|}{4,33} \\
\hline & & M2 & 2,47 & 0,00 & 0,99 & \multicolumn{2}{|c|}{4,61} \\
\hline & \multirow{2}{*}{ Feijão-de-porco } & M1 & 1,77 & 0,00 & 0,94 & \multicolumn{2}{|c|}{4,43} \\
\hline & & M2 & 2,47 & 0,00 & 0,97 & \multicolumn{2}{|c|}{4,18} \\
\hline & \multirow{2}{*}{ Nabo forrageiro } & M1 & 2,07 & 0,00 & 1,03 & \multicolumn{2}{|c|}{4,50} \\
\hline & & M2 & 2,33 & 0,00 & 0,96 & \multicolumn{2}{|c|}{4,12} \\
\hline & \multirow{2}{*}{ Coquetel } & M1 & 2,40 & 0,00 & 1,00 & \multicolumn{2}{|c|}{4,48} \\
\hline & & M2 & 1,83 & 0,00 & 1,12 & \multicolumn{2}{|c|}{4,13} \\
\hline & \multirow{2}{*}{ Plantas daninhas } & M1 & 1,93 & 0,00 & 1,06 & \multicolumn{2}{|c|}{4,56} \\
\hline & & M2 & 2,40 & 0,00 & 0,98 & \multicolumn{2}{|c|}{4,30} \\
\hline \multirow{2}{*}{\multicolumn{2}{|c|}{ Média }} & M1 & 1,95 & 0,00 & 1,04 & & \\
\hline & & M2 & 2,30 & 0,00 & 1,00 & & \\
\hline & $\mathrm{V}$ (a) \% & & 22,54 & 0,00 & 26,02 & & \\
\hline
\end{tabular}

Letras minúsculas comparam as médias dos sistemas de manejo do material vegetal (M1 e M2). Médias seguidas de mesma letra na coluna não diferem estatisticamente entre si pelo teste $\mathrm{F}$. ${ }^{* *}$ significativo a $1 \%$. ${ }^{*}$ significativo a $5 \%$. ${ }^{\text {ns }}$ não significativo pelo teste $\mathrm{F}$ a $5 \%$ de probabilidade.

material vegetal sobre os teores de nutrientes nas folhas do milho (Tabela 7). Nesse ponto, é conveniente levar em consideração a fertilidade desse solo, cultivado em sistema de cultivo orgânico. Ainda assim, observou-se tendência de superioridade dos tratamentos com incorporação do material vegetal em relação ao cultivo mínimo, provavelmente pela mineralização mais rápida dos nutrientes nesse último sistema ou, então, melhor distribuição dos nutrientes no estrato superficial do solo (0 a $20 \mathrm{~cm}$ ).
Os teores foliares de $\mathrm{N}, \mathrm{S}, \mathrm{Cu}, \mathrm{Fe}, \mathrm{Mn}$ e $\mathrm{Zn}$ ficaram dentro da faixa considerada crítica para a cultura em todos os tratamentos utilizados (Tabela 7), conforme Martinez et al. (1999). Da mesma forma, os teores de fósforo encontraram-se dentro do que é considerado suficiente, à exceção do milho cultivado em sistema de manejo convencional com a crotalária, em que os teores ficaram acima dos valores de referência. Diferentemente dos demais nutrientes, em todos os tratamentos os teores de potássio ficaram acima dos 
valores de referência preconizados para o milho.

Também foram observados teores acima dos valores de referência para o cálcio, nas plantas de milho cultivadas em sucessão à crotalária em cultivo convencional, e boro, em sucessão ao feijão-de-porco e nabo forrageiro em cultivo convencional (Tabela 7). Nos demais tratamentos, os teores desses nutrientes ficaram dentro da faixa crítica esperada para a cultura do milho.

Quanto ao magnésio, os teores foliares estiveram abaixo da faixa crítica considerada adequada para a cultura do milho quando no sistema de cultivo mínimo, especialmente em sucessão ao coquetel e às plantas daninhas (Tabela 7), em que houve manifestação de sintomas visuais de deficiência nutricional desse nutriente.

Os baixos teores foliares de magnésio, com consequentes sintomas de deficiência visual, podem ser relacionados à maior disponibilidade de potássio no solo decorrente da maior liberação de $\mathrm{K}$ pelos adubos, sobretudo no sistema de cultivo mínimo, onde houve maior concentração do nutriente (Tabela 6). Relações potássio/magnésio elevadas no solo

Tabela 7 - Teores foliares de nitrogênio $(\mathrm{N})$, fósforo $(\mathrm{P})$, potássio $(\mathrm{K})$, cálcio $(\mathrm{Ca})$, magnésio $(\mathrm{Mg})$, boro $(\mathrm{B})$, cobre $(\mathrm{Cu})$, ferro $(\mathrm{Fe})$, manganês $(\mathrm{Mn})$ e zinco $(\mathrm{Zn})$, em função da adubação verde e do sistema de manejo. Montes Claros-MG, 2011

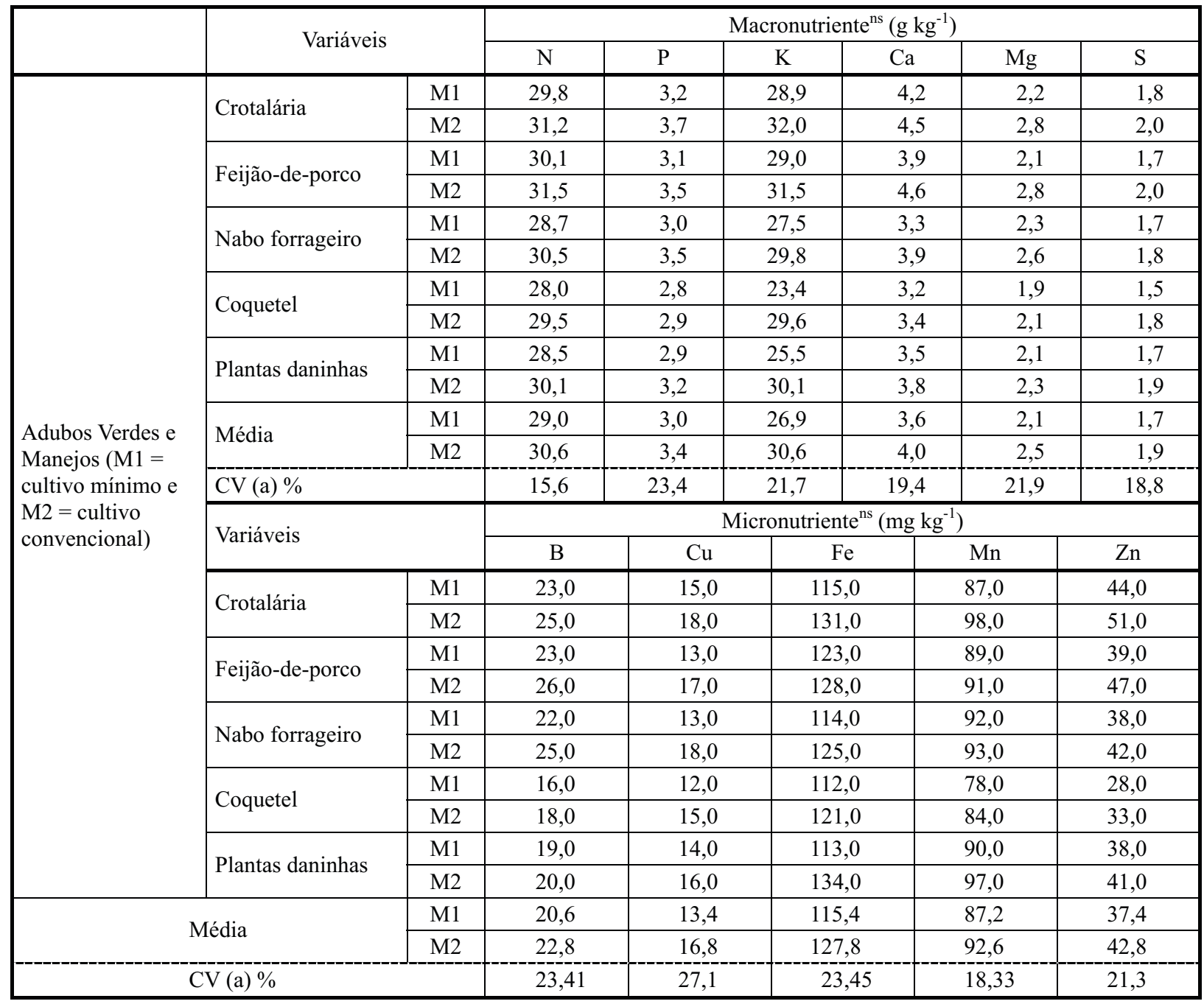

${ }^{\text {ns }}$ não significativo pelo teste $\mathrm{F}$ a $5 \%$ de probabilidade. 
inibem a absorção de magnésio por meio da inibição competitiva pelos sítios de absorção de nutrientes das raízes (Malavolta et al., 1997). Por outro lado, a maior disponibilidade de $\mathrm{K}$ no solo não influenciou os teores foliares de cálcio (Tabela 7), possivelmente pela natureza do material de origem da região, rico em carbonato de cálcio, o que confere ampla distribuição desse cátion nas superficies de troca das argilas.

A dinâmica do magnésio no solo pode ter influenciado as eficiências de absorção e utilização de fósforo, principalmente no sistema de cultivo mínimo, em que foi verificada ligeira redução nos teores foliares desse nutriente (Tabela 6). Segundo Malavolta et al. (1997), Mg e P apresentaram um relacionamento sinergístico no processo de absorção iônica radicular. Esses autores explicam que o magnésio faz parte de enzimas fosforilativas ligadas ao metabolismo do fósforo.

Os teores foliares de magnésio (Tabela 7) foram também menores nos tratamentos em que houve maiores valores de $\mathrm{pH}$ do solo no sistema de cultivo mínimo (Tabela 6). Esse sistema, devido à decomposição mais lenta da palhada em relação ao sistema convencional, pode ter proporcionado maior incremento nos teores de amônio. No sistema convencional, a incorporação dos resíduos favorece o processo de nitrificação pelos microrganismos do solo, ou seja, a transformação do $\mathrm{N}$ amoniacal em $\mathrm{N}$ nitrato, com consequente diminuição do $\mathrm{pH}$ do solo (Cantarella, 2007). Essa maior disponibilidade de $\mathrm{N}$ amoniacal $\left(\mathrm{NH}_{4}^{+}\right)$compete com o magnésio $\left(\mathrm{Mg}^{2+}\right)$ pelos sítios de absorção radicular desses nutrientes (Malavolta et al., 1999), explicando os menores teores foliares nos tratamentos com cultivo minimo (Tabela 7). Salienta-se aqui o papel do magnésio na eficiência fotossintética dos vegetais, como fundamental componente da clorofila, sobretudo do milho, planta C4 cuja demanda por energia metabólica é superior à requerida por plantas de metabolismo C3 Por essas razões, embora não se tenha observado redução em produtividade em parcelas com menores teores de $\mathrm{Mg}$, em cultivos sequentes a maior deficiência desse nutriente pode comprometer o rendimento do sistema.
O estudo demonstrou a influência das espécies e manejos de adubos verdes em condições de cultivo orgânico do milho, sob altas temperaturas e intensidade luminosa. Conclui-se que o pré-cultivo da crotalária, do feijão-de-porco, do nabo forrageiro e do coquetel de adubos permitem maiores ganhos em produtividade. Constatou-se que o estande é fortemente influenciado pela prática, principalmente com a utilização de plantas daninhas como adubação verde, onde a redução significativa do número de plantas por hectare pode indicar uma provável ação de interferência. Por outro lado, a utilização do manejo de cultivo convencional do material vegetal resulta em aumento do estande da cultura e, no manejo de cultivo mínimo, em maior crescimento, sem, contudo, influenciarem nas produtividades de espigas. A qualidade das espigas tem influência positiva do volume de resteva deixada pela cultura antecessora e os teores de nutrientes nas folhas do milho, quando em manejo de incorporação do material, apresentam relações $\mathrm{K} / \mathrm{Mg}$ mais balanceadas. O manejo de cultivo minimo influencia nas características químicas do solo, levando à concentração de $\mathrm{P}$ e $\mathrm{K}$ na porção mais superficial.

\section{AGRADECIMENTOS}

Ao Conselho Nacional de Desenvolvimento Científico e Tecnológico (CNPq) e à Fundação de Amparo à Pesquisa do Estado de Minas Gerais (FAPEMIG), pela concessão de bolsas e pelos recursos para a realização desta pesquisa.

\section{LITERATURA CITADA}

AL-BAKEIR, H. M. Yield, growth rate, and nutrient content of corn (Zea mays L.) hybrids. Hebron University Res. J., v. 1, p. $24-39,2003$

ALVARENGA, R. C. et al. Características de alguns adubos verdes de interesse para a conservação e recuperação dos solos. Pesq. Agropec. Bras., v. 30, n. 1, p. 175-185, 1995.

ALVAREZ V., V.H. et al. Interpretação dos resultados das análises de solos. In: RIBEIRO, A. C. et al. (Ed.).

Recomendações para o uso de corretivos e fertilizantes em Minas Gerais - 5 a Aproximação. Viçosa, MG: 1999. $359 \mathrm{p}$

Planta Daninha, Viçosa-MG, v. 30, n. 3, p. 505-516, 2012 
ANDRADE, A. T;; FERNANDES, L.A.; FAQUIN, V. Organic residue, limestone, gypsum and phosphorus adsorption by lowland soils. Sci. Agríc., v. 59, n. 2, p. 349-355, 2002.

BARKER, D. N.; MUSGRAVE, R. B. The effect of low level moisture stresses on the rate of apparent photosynthesis in corn. Crop Sci., v. 4, n. 3, p.249-253. 1964.

BERGAMASCHI, H. et al. Distribuição hídrica no período crítico do milho e produção de grãos. Pesq. Agropec. Bras., v. 39, n. 9 , p. 831-839, 2004.

BHOWMIK, P. C.; DOLL, J. D. Corn and soybean response to allelopathic effects of weed and crop residues. Agron. J., v. 74, p. 601-606, 1982

BHOWMIK, P. C.; DOLL, J. D. Allelopathic effects of annual weed residues on growth and nutrient uptake of corn and soybeans. Agron. J., v. 76, p. 383-388, 1984

CANTARELLA, H. Nitrogênio. In: NOVAIS, R. F. et al. (Eds.). Fertilidade do solo. Viçosa, MG: Sociedade Brasileira de Ciência do Solo, 2007. p. 375-470.

\section{EMPRESA BRASILERIA DE PESQUISA AGRICOLA -} Serviço Nacional de Levantamento e Conservação de Solo: manual de métodos de análise de solo. Rio de Janeiro: 1997. $212 \mathrm{p}$.

EPSTEIN E.; BLOOM, A. J. Nutrição mineral de plantas: princípios e perspectivas. Londrina: Planta, 2006. 393 p.

FALUBA, J. S. et al. Potencial genético da população de milho UFV 7 para o melhoramento em Minas Gerais. Ci. Rural, v. 40, n. 6, p. 1250-1256, 2010.

FERREIRA, A. G.; AQUILA, M. E. A. Alelopatia: uma área emergente da ecofisiologia. R. Bras. Fisiol. Veg., v. 12, p. 175-204, 2000. (Edição Especial)

FERNANDES, L. A. et al. Preparo do solo e adubação nitrogenada na produção de grãos e matéria seca e acúmulo de nutrientes pelo milho. Pesq. Agropec. Bras., v. 34, n. 9, p. $1691-1698,1999$

FERMINO, M. H. et al. Caracterização física e química de materiais alternativos para composição de substratos para plantas: 1. Resíduos industriais e agrícolas. In: KÄMPF, N. A.; FERMINO, M. H. (Eds.). Substratos para plantas: a base da produção vegetal em recipientes. Porto Alegre: Gênesis, 2000. p. 241-248

FERRAZ, E. C. Fisiologia. In: KRUG, C. A. et al. Cultura e adubação do milho. São Paulo: Instituto Brasileiro de Potassa, 1966. p. 369-378

FORSTHOFER, E. L. et al. Desenvolvimento fenológico e agronômico de três híbridos de milho em três épocas de semeadura. Ci. Rural, v. 34, n. 5, p. 1341-1348, 2004.
GARCIA, J. C.; MATTOSO, M. J.; DUARTE, J. O Importância do milho em Minas Gerais. Inf. Agropec., v. 27, n. 1, p. 7-12, 2006.

INSTITUTO BRASILEIRO DE GEOGRAFIA E ESTATÍSTICA - IBGE. Levantamento sistemático da produção agrícola. 2009 Disponível em: $<$ http:// www.ibge.gov.br>. Acesso em: 18 maio de 2011.

MALAVOLTA, E.; GARGANTINI, H. Nutrição mineral e adubação. In: KRUG, C. A. et al. Cultura e adubação do milho. São Paulo: Instituto Brasileiro de Potassa, 1966. p. $381-424$

MALAVOLTA, E. et al. Avaliação do estado nutricional das plantas: princípios e aplicações. 2.ed. Piracicaba: Associação Brasileira para Pesquisa da Potassa e do Fosfato, 1997. 319 p.

MARTINEZ, H. E. P. et al. Diagnose foliar. In: RIBEIRO, A. C. et al. Recomendações para o uso de corretivos e fertilizantes em Minas Gerais: $5^{\mathrm{a}}$ aproximação. Viçosa, MG: Comissão de Fertilidade do Solo do Estado de Minas Gerais, 1999. p. 143-168

NOVAIS, R. F.; SMYTH, T. J.; NUNES, F. N. VIII - Fósforo. In: NOVAIS, R. F. et al. (Eds.). Fertilidade do solo. Viçosa, MG: Sociedade Brasileira de Ciência do Solo, 2007. 472-537.

OHLAND, R. A. A. et al. Culturas de cobertura do solo e adubação nitrogenada no milho em plantio direto. $\mathbf{C i}$. Agrotec., v. 29, n. 3, p. 538-544, 2005.

RAO, M. R.; MATHUVA, M. N. Legumes for improving maize yields and income in semi-arid Kenya. Agric. Ecosys. Environ., v. 78, p. 123-137, 2000.

ROSOLEM, C. A. et al. Lixiviação de potássio no solo de acordo com suas doses aplicadas sobre palha de milheto. $\mathbf{R}$. Bras. Ci. Solo, v. 30, n. 5, p. 813-819, 2006.

SAINJU, U. M. et al. Carbon accumulation in cotton, sorghum, and underlying soil as influenced by tillage, cover crops, and nitrogen fertilization. Plant Soil, v. 273, n. 1, p. 219-234, 2005.

SOUZA, L. S.; VELINI, E. D.; MAIOMONI-RODELLA, R. C. S. Efeito alelopático de plantas daninhas e concentrações de capim-braquiária (Brachiaria decumbens) no desenvolvimento inicial de eucalipto (Eucalyptus grandis).

Planta Daninha, v. 21, n. 3, p. 343-354, 2003.

SULLIVAN, P. Overview of cover crops and green manures. Fayetteville: ATTRA/ National Center for Appropriate Technology, 2003.16 p.

TSUNECHIRO, A.; DUARTE, J. O.; MATOSO, M. J. Aspectos econômicos da comercialização e custo de produção do milho verde. In: PEREIRA FILHO, I. A. (Ed.). O cultivo do milho verde. Sete Lagoas: Empresa Brasileira de Pesquisa Agropecuária, 2002. p. 179-191 